\title{
Total knee arthroplasty in the younger patient: challenges and solutions
}

\author{
This article was published in the following Dove Press journal: \\ Orthopedic Research and Reviews \\ 30 April 2015 \\ Number of times this article has been viewed
}

\author{
James A Keeney \\ Department of Orthopaedic Surgery, \\ University of Missouri School of \\ Medicine, Columbia, MO, USA
}

\begin{abstract}
Total knee arthroplasty is being performed for an increasing number of younger patients with osteoarthritis. Several studies have demonstrated a high prevalence of residual symptoms among younger total knee arthroplasty patients and functional activity lower than expectations based on age and preoperative diagnosis. Limited studies have specifically focused on specific techniques or implant designs on this patient population, but have not identified optimal approaches. Limiting the most common complications that lead to early surgical revision, infection and instability, is important to ensure both short-term symptom resolution and long-term implant survivorship.
\end{abstract}

Keywords: total knee arthroplasty, TKA, younger patient, outcomes, implant selection, surgical techniques

\section{Introduction}

Total knee arthroplasty (TKA) is being performed with increasing frequency for younger patients with advanced clinical and radiographic knee arthritis. Kurtz et al have reported that patients less than 55 years of age comprise the most rapidly growing subset of patients undergoing TKA in the United States and have estimated that as many as 900,000 total knee replacements may be performed in this patient group by the year $2030 .{ }^{1}$ Studies reporting outcomes using traditional legacy scales have demonstrated substantial improvement in mean clinical and functional outcome scores following TKA in younger patients with implant survival between $90 \%$ and $99 \%$ during the first postoperative decade and between $85 \%$ and $96 \%$ during the second postoperative decade. ${ }^{2}$ In spite of the general success reported among younger TKA patients, many individual patients do not improve as much as expected. Recent studies have suggested that between $30 \%$ and $50 \%$ of younger TKA patients experience residual symptoms during various functional activities. ${ }^{3,4}$ The use of newer implant designs has not necessarily resulted in a reduction in symptoms after TKA. ${ }^{5}$

Because younger TKA patients are more likely to engage in higher activity levels or to require implant durability over a longer time interval, implant technologies and surgical techniques should be aligned to optimize both short-term symptomatic improvement and long-term arthroplasty survivorship. There is a trend among surgeons in North America to accept partial knee replacement in younger patients, either as a definitive treatment or as a bridge to a later total knee replacement procedure. The latter approach is generally based on acceptance of a higher early failure rate, with an expectation that adverse symptoms will be less common in a partial replacement compared with a TKA and that conversion from a unicompartmental to TKA will be
Correspondence: James A Keeney Department of Orthopaedic Surgery, University of Missouri School of Medicine, II 00 Virginia Avenue, Columbia, MO 6520I, USA

Tel +l 5738826449

Fax +I 5738828200

Email keeneyj@health.missouri.edu 
more predictable in outcome than a revision of a failed total knee replacement.

This paper will review the present published evidence on both partial and TKA in the younger patient, focusing on patient demographic characteristics, implant selection and surgical technique, and reported functional outcomes and arthroplasty survivorship.

\section{Challenges in the literature Defining the patient}

Although several studies have reported mid-term outcomes (up to 12 years) after total knee replacement performed in younger patients, only a few of them selectively evaluated outcomes among patients who had a diagnosis of osteoarthritis. ${ }^{6-12}$ A systematic review of studies performed before 2010 indicated that the outcomes of TKA were largely successful among these younger patients, with substantial increases in both pain-predominated clinical activity scales and function based outcome scores. ${ }^{13}$ However, while most authors have broadly characterized younger TKA patients as "active", this generalization has not been supported. The highest level of activity was reported by Odland et al, who noted that $65 \%$ of their patients had returned to active labor or some form of recreational sport activity. The mean UCLA (University of California, Los Angeles) activity score reported was 5.5 points, which correlates with the average patient engaging in moderate activity such as unlimited housework or shopping. ${ }^{14,15}$ Diduch et al reported that the younger TKA patient activity had improved significantly from 1.3 points (range $0-4$ points) preoperatively to 3.5 points (range $1-6) .{ }^{6}$ Long et al reported an extended follow-up of this same patient cohort, noting that increased postoperative activity levels were sustained by a mean Tegner score of 3.0 points at a mean of 25 years after TKA. ${ }^{9}$ This activity level correlates with recreational swimming or going on a recreational hike. Although patients were characterized as "active", Long et al reported that only $25 \%$ of patients were engaged at an activity level of 4 or higher, indicating participation in either moderate demand work such as driving a truck, cycling, cross-country skiing, or jogging on a level surface at least two times per week. ${ }^{9}$ The mean Tegner activity score reported in both of these studies is substantially less than what Briggs et al reported among patients with normal knees (mean 5.7 points). ${ }^{16}$ General improvements in mean activity and outcome scores are not universally experienced by younger patients, with as many as $45 \%$ of younger TKA patients not being able to increase their activity level after surgery and approximately $15 \%$ of them functioning at a lower level than before surgery. ${ }^{13}$

\section{Defining optimal implants and techniques}

Deciding what implant is most appropriate for an individual patient has to take into account the nature of the arthritic disease process on the knee joint. Patients with a focal disease process localized to a single joint compartment - medial, lateral, or patellofemoral - may benefit from a unicompartmental (partial) knee replacement, if they are reasonably willing to modify activity levels. Non-arthroplasty options (proximal tibial osteotomy, distal femoral osteotomy, or tibial tubercle osteotomy) should be considered for high activity patients with malalignment and mild to moderate radiographic arthritis. Patients with more diffuse arthritic disease, will benefit more predictably from a TKA.

\section{Medial unicompartmental knee arthroplasty}

Traditionally, unicompartmental arthroplasty was reserved for lower demand patients, older patients with limited deformity ( $<10$ degrees), mild flexion contracture ( $<10$ degrees), intact cruciate ligaments, and moderate physical size (weight $<90 \mathrm{~kg}$ ). For real or perceived advantages, there is an increased interest in partial knee replacement among younger patients. Lombardi et al reported that patients undergoing unicompartmental arthroplasty had an earlier recovery of range of motion and higher early clinical outcome scores than patients treated with a conventional, cruciate-retaining total knee replacement. ${ }^{17}$ Consideration of unicompartmental knee arthroplasty (UKA) over osteotomy may be influenced by less familiarity with the surgical technique or concerns over high reported complication rates (30\%) among patients who subsequently are converted from an osteotomy to a TKA. ${ }^{18}$ While there are appropriate reasons to consider unicompartmental knee replacement in younger patients, historical data from earlier component designs suggest that younger patients with unicompartmental arthroplasties are at risk of substantially higher failure rates within the first 15 years after surgery. ${ }^{19-23}$ Gioe et al reported a 32\% failure rate for unicompartmental arthroplasties in young patients from a community orthopedic surgery registry. ${ }^{20}$ Niinimäki et al reported a 2.2-fold increased risk of revision among UKA compared with TKA patients at an average of 6.2 years after surgery. ${ }^{22}$ Bini et al reported that the risk of UKA revision was 4.5 times more likely when performed in younger patients and 2.2 times more likely when the procedure is performed by surgeons with a volume of less than 12 cases per year. ${ }^{19}$ Parratte et al compared the results of fixed and mobile bearing UKAs performed in patients with a relatively low body mass index (average $26 \mathrm{~kg} / \mathrm{m}^{2}$ ) and noted no significant differences at an average of 17 years after surgery. There were 
similar rates of revision in both mobile bearing $(15 \%)$ and fixed bearing (12\%) designs. ${ }^{24}$

When medial UKA is selected as a treatment option, careful attention to detail during the surgery is necessary to ensure appropriate alignment is achieved, especially with respect to an appropriate reapproximation of tibial slope. Hernigou and Deschamps recommended avoiding a posterior slope greater than 7 degrees with unicompartmental arthroplasty after noting a higher incidence of late anterior cruciate ligament (ACL) failure among patients and increased revision risk among patients with increased tibial slope. ${ }^{25}$ Nunley et al have noted that as many as $17 \%$ of patients have native posterior tibial slope $>10$ degrees. ${ }^{26}$ Additional study will be needed to define whether reconstruction with a similar degree of slope in these patients is appropriate, whether reducing the slope will be preferable, or whether UKA should be avoided in these patients.

\section{Patellofemoral arthroplasty}

At the present time, there is little specific evidence regarding the outcomes of patellofemoral arthroplasty (PFA) specifically in younger patients. PFA is an attractive option for younger patients with isolated patellofemoral disease when considering that the results of extensor mechanism realignment procedures are not uniformly successful - with as many as $35 \%$ reported to have persistent pain after surgery. ${ }^{27}$ While Meding et al reported more predictable outcomes in younger patients undergoing TKA than undergoing PFA using an earlier component design, improvements in second generation designs have received favorable early reports. ${ }^{28,29}$ Longer follow-up will be needed to define the outcomes of this procedure among younger patients who may wish to remain active.

\section{TKA}

At the present time, there is little published guidance for specific decisions in implant selection or surgical technique for TKA in younger patients. Most surgeons will consider several considerations when performing TKA in younger patients because of an expected requirement for the knee to be durable. While efforts to improve implant design characteristics have continued over the past two decades, the literature is mixed on whether these have translated into better performance.

\section{Implant design}

At the present time, no literature has demonstrated more favorable outcomes in younger patients based on TKA design. Kim et al have reported similar improvement in pain and function for both mobile bearing and fixed bearing knee replacements when performed for patients $\leq 50$ years of age. ${ }^{8}$ The literature is mixed in defining whether implant modifications designed to enhance TKA performance or durability have resulted in improvements perceived by patients. Hamilton et al reported clinically meaningful improvement in knee range of motion and functional scores when comparing a contemporary implant with an earlier generation design from the same manufacturer. ${ }^{30}$ In contrast, Nunley et al reported that younger TKA patients were more likely to experience undesirable mechanical symptoms (grinding, popping, or clicking) from contemporary implant designs - rotating platform (43\%) and sex specific (37\%) - compared with an older cruciate retaining (CR) (19\%) implant design. ${ }^{5}$ They also reported twice as many patients had difficulty getting up from a chair (37\%) with these newer designs compared with patients who had received an older CR implant (19\%). There is also some renewed interest in bicruciate retaining TKA, as this may help to reduce clinical instability associated with $\mathrm{CR}$ and posterior stabilized designs which leave younger patients with an ACL deficient knee. However, there are no studies on this implant technology specifically used among younger patients who would be most likely to subject the TKA prosthesis to these types of mechanical loading. Cloutier et al had reported favorable clinical and functional outcome scores and 95\% 10-year implant survival on an ACL sparing implant, but generalizing the results of this study to a young TKA population is limited by the average ( 77.3 years) and minimum age (59 years) of patients who received these implants. ${ }^{31}$ The technique associated with the use of a bicruciate sparing knee is less forgiving than traditional implant designs. While these implants hold some promise for the most highly active patients, more study is needed to define whether both symptomatic improvement and long-term durability of prosthetic implant fixation are achieved.

\section{Soft tissue balancing}

Instability has been identified as the most common reason for TKA revision within the first 2 years after surgery. ${ }^{32}$ At the present time, significant attention is being given to ways to optimize TKA soft tissue balance and consideration over whether targeting a traditional mechanical axis can consistently produce a balanced soft tissue envelope that is maintained throughout the range of motion arc. Parratte et al reported that patients were no more likely to undergo revision surgery when component alignment was achieved within 3 degrees of a neutral mechanical 
alignment, than if the knee had been placed outside of this alignment goal. ${ }^{33}$ Other investigators have proposed a kinematic alignment target, and limited studies to date have suggested that this more successfully restores soft tissue balance around the knee. ${ }^{3,34}$ Custom cutting guides were introduced to help decrease variability in surgeon ability to achieve composite coronal and sagittal alignment targets and potentially decrease blood loss by allowing the procedure to be accomplished without instrumentation of the femur and tibia. While these technologies may have potential, several studies have pointed out limitations including potential need for the surgeon to adapt operative technique to successfully accomplish the procedure. ${ }^{35-37}$ Regardless of whether a mechanical or kinematic axis is targeted, understanding both tibiofemoral alignment and the individual contributions of the femur and tibia to three-dimensional knee position, is important to balance deformity correction through the knee joint. While Luyckx et al suggest that experienced surgeons can use either a measured resection or gap balancing technique to achieve soft tissue balance in the flexion space that matches the extension space, Dennis et al have reported reduced femoral implant lift-off during flexion activity with the use of gap balancing techniques. ${ }^{38,39}$ However, the effectiveness of these approaches has not been specifically assessed in younger patients. Regardless of approach, it is important for the surgeon treating younger TKA patients to recognize when it is appropriate to accept less aggressive coronal or sagittal plane deformity correction, when there is the potential to increase soft tissue laxity and symptomatic instability. Corrections that are made to deformity in the extension space need to be adequately balanced against corrections made in the flexion space in order to maintain a balanced soft tissue envelope.

\section{Bearing surfaces}

Over time, the major cause of revisions continues to be related to bearing surface wear and the biological responses to particulate polyethylene wear debris. Odland et al reported that aseptic loosening or osteolysis resulted in revision for $16 \%$ of TKAs performed in younger patients at a mean of 12 years after surgery. ${ }^{14}$ Highly cross-linked polyethylene has been widely accepted in total hip arthroplasty, with limited reports demonstrating low wear rates even in highly active patients. ${ }^{37}$ While limited studies have reported that highly cross-linked polyethylenes can be used without an increased risk of early failure in TKA, some authors have expressed that caution should be exercised with the use of highly cross-linked polyethylene due to a potential for mechanical failure that has not been specifically defined. ${ }^{40-45}$

\section{Managing pain and limiting complications}

Successful total knee replacement requires that several conditions are met. Patient comorbidities need to be optimized or managed effectively to reduce the risks of perioperative wound complications or exacerbation of medical conditions. The surgical procedure needs to be accomplished with adequate proficiency to position components near intended alignment and to create a balanced soft tissue envelope that will allow restoration of function without instability.

Patients need to be able to effectively engage postoperative rehabilitation to recover functional motion and to progressively increase strength over the course of several months after surgery. Prophylaxis provided to reduce the risk of perioperative complications, such as venous thromboembolism, should be performed using techniques that provide a balance between prevention and the introduction of additional clinical concerns. Early postoperative pain control is an essential component of early recovery. Multi-modal pain management approaches including regional analgesia, intra-articular injections, long- and short-acting pain medications, anti-inflammatory medications, and adjunctive modalities may be helpful in attenuating early postoperative pain response and allowing patients to more effectively engage early postoperative recovery to recover functional range of motion early after surgery with a gradual recovery of strength over several months after surgery. Limiting the risks of infection and instability is critical as these complications have been reported as the most frequent cause of early failure. ${ }^{32}$ Repeat revision TKA in younger patients for these concerns have been associated with limited improvement in functional outcome scores and a high probability for repeat revision TKA. ${ }^{46,47}$

\section{Summary}

TKA is being performed for an increasing population of younger patients. Adverse symptoms related to component malposition or soft tissue imbalance may be more readily apparent among patients who attempt to engage higher level activities after surgery compared to older patients. Acute complications related to surgical technique, including prosthetic instability, limited motion, infection, or extensor mechanism dysfunction contribute to higher cumulative revision rates and will likely affect these patients for their remaining lifetime. The present literature has not adequately described implant or technique specific outcomes related to 
younger TKA patients. Assessing long-term performance of specific implants or techniques will benefit most from study of the most highly active subset of this patient group.

\section{Disclosure}

The author has received financial payment from OrthoSensor for consultant activity, research support from Stryker, and is serving as a board member for the Society of Military Orthopedic Surgeons (SOMOS).

\section{References}

1. Kurtz SM, Lau E, Ong K, Zhao K, Kelly M, Bozic KJ. Future young patient demand for primary and revision joint replacement: national projections from 2010 to 2030. Clin Orthop Relat Res. 2009;467(10): 2606-2612.

2. Keeney JA, Eunice S, Pashos G, Wright RW, Clohisy JC. What is the evidence for total knee arthroplasty in young patients?: a systematic review of the literature. Clin Orthop Relat Res. 2011;469(2):574-583.

3. Nam D, Nunley RM, Barrack RL. Patient dissatisfaction following total knee replacement: a growing concern? Bone Joint J. 2014;96-B (11 Supple A):96-100.

4. Parvizi J, Nunley RM, Berend KR, et al. High level of residual symptoms in young patients after total knee arthroplasty. Clin Orthop Relat Res. 2014;472(1):133-137.

5. Nunley RM, Nam D, Berend KR, et al. New total knee arthroplasty designs: do young patients notice? Clin Orthop Relat Res. 2015;473(1): 101-108.

6. Diduch DR, Insall JN, Scott WN, Scuderi GR, Font-Rodriguez D. Total knee replacement in young, active patients. Long-term follow-up and functional outcome. J Bone Joint Surg Am. 1997;79(4):575-582.

7. Duffy GP, Crowder AR, Trousdale RR, Berry DJ. Cemented total knee arthroplasty using a modern prosthesis in young patients with osteoarthritis. J Arthroplasty. 2007;22(6 Suppl 2):67-70.

8. Kim YH, Kim JS, Choe JW, Kim HJ. Long-term comparison of fixedbearing and mobile-bearing total knee replacements in patients younger than fifty-one years of age with osteoarthritis. J Bone Joint Surg Am. 2012;94(10):866-873.

9. Long WJ, Bryce CD, Hollenbeak CS, Benner RW, Scott WN. Total knee replacement in young, active patients: long-term follow-up and functional outcome: a concise follow-up of a previous report. $J$ Bone Joint Surg Am. 2014;96(18):e159.

10. Lonner JH, Hershman S, Mont M, Lotke PA. Total knee arthroplasty in patients 40 years of age and younger with osteoarthritis. Clin Orthop Relat Res. 2000;(380):85-90.

11. Stern SH, Bowen MK, Insall JN, Scuderi GR. Cemented total knee arthroplasty for gonarthrosis in patients 55 years old or younger. Clin Orthop Relat Res. 1990;(260):124-129.

12. Tai CC, Cross MJ. Five- to 12-year follow-up of a hydroxyapatitecoated, cementless total knee replacement in young, active patients. J Bone Joint Surg Br. 2006;88(9):1158-1163.

13. Keeney JA, Nunley RM, Wright RW, Barrack RL, Clohisy JC. Are younger patients undergoing TKAs appropriately characterized as active? Clin Orthop Relat Res. 2014;472(4):1210-1216.

14. Odland AN, Callaghan JJ, Liu SS, Wells CW. Wear and lysis is the problem in modular TKA in the young OA patient at 10 years. Clin Orthop Relat Res. 2011;469(1):41-47.

15. Amstutz HC, Thomas BJ, Jinnah R, Grogan T, Yale C. Treatment of primary osteoarthritis of the hip: a comparison of total hip and surface replacement arthroplasty. J Bone Joint Surg Am. 1984;66(2): 228-241.

16. Briggs KK, Steadman JR, Hay CJ, Hines SL. Lysholm score and Tegner activity level in individuals with normal knees. Am J Sports Med. 2009;37(5):898-901.
17. Lombardi AV Jr, Berend KR, Walter CA, Aziz-Jacobo J, Cheney NA. Is recovery faster for mobile-bearing unicompartmental than total knee arthroplasty? Clin Orthop Relat Res. 2009;467(6):1450-1457.

18. Jackson M, Sarangi PP, Newman JH. Revision total knee arthroplasty. Comparison of outcome following primary proximal tibial osteotomy or unicompartmental arthroplasty. J Arthroplasty. 1994;9(5):539-542.

19. Bini S, Khatod M, Cafri G, Chen Y, Paxton EW. Surgeon, implant, and patient variables may explain variability in early revision rates reported for unicompartmental arthroplasty. J Bone Joint Surg Am. 2013;95(24):2195-2202.

20. Gioe TJ, Novak C, Sinner P, Ma W, Mehle S. Knee arthroplasty in the young patient: survival in a community registry. Clin Orthop Relat Res. 2007:464:83-87.

21. Lyons MC, MacDonald SJ, Somerville LE, Naudie DD, McCalden RW. Unicompartmental versus total knee arthroplasty database analysis: is there a winner? Clin Orthop Relat Res. 2012;470(1):84-90.

22. Niinimäki T, Eskelinen A, Mäkelä K, et al. Unicompartmental knee arthroplasty survivorship is lower than TKA survivorship: a 27-year Finnish registry study. Clin Orthop Relat Res. 2014;472(5):1496-1501.

23. Pennington DW, Swienckowski JJ, Lutes WB, Drake GN. Unicompartmental knee arthroplasty in patients sixty years of age or younger. J Bone Joint Surg Am. 2003;85-A(10):1968-1973.

24. Parratte S, Pauly V, Aubaniac JM, Argenson JN. No long-term difference between fixed and mobile medial unicompartmental arthroplasty. Clin Orthop Relat Res. 2012;470(1):61-68.

25. Hernigou P, Deschamps G. Posterior slope of the tibial implant and the outcome of unicompartmental knee arthroplasty. J Bone Joint Surg Am. 2004;86-A(3):506-511.

26. Nunley RM, Nam D, Johnson SR, Barnes CL. Extreme variability in posterior slope of the proximal tibia: measurements on 2395 CT scans of patients undergoing UKA? J Arthroplasty. 2014;29(8):1677-1680.

27. Atkinson HD, Bailey CA, Anand S, Johal P, Oakeshott RD. Tibial tubercle advancement osteotomy with bone allograft for patellofemoral arthritis: a retrospective cohort study of 50 knees. Arch Orthop Trauma Surg. 2012;132(4):437-445.

28. Meding JB, Wing JT, Keating EM, Ritter MA. Total knee arthroplasty for isolated patellofemoral arthritis in younger patients. Clin Orthop Relat Res. 2007;464:78-82.

29. Leadbetter WB, Kolisek FR, Levitt RL, et al. Patellofemoral arthroplasty: a multi-centre study with minimum 2-year follow-up. Int Orthop. 2009;33(6):1597-1601.

30. Hamilton DF, Burnett R, Patton JT, et al. Implant design influences patient outcome after total knee arthroplasty: a prospective double-blind randomised controlled trial. Bone Joint J. 2015;97-B(1):64-70.

31. Cloutier JM, Sabouret P, Deghrar A. Total knee arthroplasty with retention of both cruciate ligaments. A nine to eleven-year follow-up study. J Bone Joint Surg Am. 1999;81(5):697-702.

32. Schroer WC, Berend KR, Lombardi AV, et al. Why Are Total Knees Failing Today? Etiology of Total Knee Revision in 2010 and 2011 J Arthroplasty. 2013;28(8 Suppl):116-119.

33. Parratte S, Pagnano MW, Trousdale RT, Berry DJ. Effect of postoperative mechanical axis alignment on the fifteen-year survival of modern, cemented total knee replacements. J Bone Joint Surg Am. 2010;92(12): 2143-2149.

34. Howell SM, Papadopoulos S, Kuznik KT, Hull ML. Accurate alignment and high function after kinematically aligned TKA performed with generic instruments. Knee Surg Sports Traumatol Arthrosc. 2013;21(10):2271-2280.

35. Nunley RM, Ellison BS, Zhu J, et al. Do patient-specific guides improve coronal alignment in total knee arthroplasty? Clin Orthop Relat Res. 2012;470(3):895-902.

36. Stronach BM, Pelt CE, Erickson J, Peters CL. Patient-specific total knee arthroplasty required frequent surgeon-directed changes. Clin Orthop Relat Res. 2013;471(1):169-174.

37. Voleti PB, Hamula MJ, Baldwin KD, Lee GC. Current data do not support routine use of patient-specific instrumentation in total knee arthroplasty. J Arthroplasty. 2014;29(9):1709-1712. 
38. Luyckx T, Peeters T, Vandenneucker H, Victor J, Bellemans J. Is adapted measured resection superior to gap-balancing in determining femoral component rotation in total knee replacement? J Bone Joint Surg Br. 2012;94(9):1271-1276.

39. Dennis DA, Komistek RD, Kim RH, Sharma A. Gap balancing versus measured resection technique for total knee arthroplasty. Clin Orthop Relat Res. 2010;468(1):102-107.

40. Babovic N, Trousdale RT. Total hip arthroplasty using highly crosslinked polyethylene in patients younger than 50 years with minimum 10-year follow-up. J Arthroplasty. 2013;28(5):815-817.

41. Hodrick JT, Severson EP, McAlister DS, Dahl B, Hofmann AA. Highly crosslinked polyethylene is safe for use in total knee arthroplasty. Clin Orthop Relat Res. 2008;466(11):2806-2812.

42. Kim YH, Park JW. Comparison of highly cross-linked and conventional polyethylene in posterior cruciate-substituting total knee arthroplasty in the same patients. J Bone Joint Surg Am. 2014;96(21):1807-1813.
43. Hambright DS, Watters TS, Kaufman AM, Lachiewicz PF, Bolognesi MP. Fracture of highly cross-linked all-polyethylene patella after total knee arthroplasty. J Knee Surg. 2010;23(4):237-240.

44. Lachiewicz PF, Geyer MR. The use of highly cross-linked polyethylene in total knee arthroplasty. J Am Acad Orthop Surg. 2011;19(3): $143-151$.

45. Sakellariou VI, Sculco T, Poultsides L, Wright T, Sculco TP. Highly cross-linked polyethylene may not have an advantage in total knee arthroplasty. HSS J. 2013;9(3):264-269.

46. Aggarwal VK, Goyal N, Deirmengian G, et al. Revision total knee arthroplasty in the young patient: is there trouble on the horizon? J Bone Joint Surg Am. 2014;96(7):536-542.

47. Stambough JB, Clohisy JC, Barrack RL, Nunley RM, Keeney JA. Increased risk of failure following revision total knee replacement in patients aged 55 years and younger. Bone Joint J. 2014;96-B(12): $1657-1662$.

\section{Publish your work in this journal}

Orthopedic Research and Reviews is an international, peer-reviewed, open access journal focusing on the patho-physiology of the musculoskeletal system, trauma, surgery and other corrective interventions to restore mobility and function. Advances in new technologies, materials, techniques and pharmacological agents are particularly welcome. The journal welcomes original research, clinical studies, reviews \& evaluations, expert opinion and commentary, case reports and extended reports. The manuscript management system is completely online and includes a very quick and fair peer-review system, which is all easy to use. Visit http://www.dovepress. com/testimonials.php to read real quotes from published authors. 